J. Amer. Soc. Hort. Sci. 121(4):680-685. 1996.

\title{
Fruit Mass Development in Three Cranberry Cultivars and Five Production Regions
}

\author{
Carolyn J. DeMoranville ${ }^{1}$ \\ Cranberry Experiment Station, University of Massachusetts, P.O. Box 569, East Wareham MA 02538
}

Joan R. Davenport ${ }^{2}$

Ocean Spray Cranberries, Inc., 1 Ocean Spray Drive, Lakeville-Middleboro, MA 02349

Kim Patten ${ }^{3}$

Long Beach Research and Extension Unit, Washington State University, Route 1 Box 570, Long Beach, WA 98631

Teryl R. Roper ${ }^{4}$

Department of Horticulture, University of Wisconsin, Madison, WI 53706

Bernadine C. Strik ${ }^{4}$

Department of Horticulture, Oregon State University, Corvallis, OR 97331

Nicholi Vorsa ${ }^{4}$

Rutgers Blueberry and Cranberry Research Station, Chatsworth, NJ 08019

Arthur P. Poole ${ }^{5}$

Coos County Extension, 290 North Central, Coquille, OR 97423

Additional index words. Vaccinium macrocarpon, growth rate, ambient air temperature

\begin{abstract}
Fruit mass development in 'Crowley', 'Pilgrim', and 'Stevens' cranberry (Vaccinium macrocarpon Ait.) was compared in five states for two seasons. Comparing all locations, 'Stevens' and 'Pilgrim' cranberries had similar growth curves with a faster growth rate than that of 'Crowley'. Regional differences in fruit development were observed. Shorter growing seasons, especially in Wisconsin, were compensated for by more rapid growth rates. Conversely, low initial mass and slower growth rates were compensated for by the longer growing season in the Pacific Northwest. Solar radiation intensity accounted for little of the variability in fruit growth. Neither growing degree days nor numbers of days were good predictors of cranberry fruit fresh mass accumulation. Instead, numbers of moderate temperature days (between 16 and $30{ }^{\circ} \mathrm{C}$ ) appeared to be key, accounting for greater than $80 \%$ of the variability in cranberry fresh biomass accumulation. The most rapid growth rates occurred when temperatures were in this range. High temperatures were limiting in New Jersey while low temperatures were limiting in Oregon and Washington. In one of two seasons, low temperatures were limiting in Wisconsin: accumulation of $0.5 \mathrm{~g}$ fresh mass took $11 \mathrm{~d}$ longer. Massachusetts had the fewest periods of temperature extremes in both seasons, resulting in the shortest number of days required to accumulate $0.5 \mathrm{~g}$ fresh mass.
\end{abstract}

The American cranberry is grown commercially in a limited number of regions in North America. Cranberry is a nondeciduous woody, perennial plant producing flowers and fruit from flower buds formed the previous season (Eck, 1990). Throughout the United States, the predominant cranberry cultivars in production are selections from the wild. Hybrid cultivars, however, offer higher yields mainly due to the production of larger fruit with greater mass. These cultivars are available and commercially grown in all of the production regions. Although growers report variations in performance of these cultivars by production regions and climatic conditions, none of these have been documented. We decided to evaluate these differences for the five major U.S. cranberry growing states. Three hybrid cultivars were selected

Received for publication 19 June 1995. Accepted for publication 4 Mar. 1996. We thank John Klueh, Technician, Univ. of Wisconsin, Madison, for assistance with statistical analyses. The cost of publishing this paper was defrayed in part by the payment of page charges. Under postal regulations, this paper therefore must be hereby marked advertisement solely to indicate this fact.

${ }^{1}$ Extension educator, cranberry specialist.

${ }^{2}$ Manager, agricultural research.

${ }^{3}$ Associate horticulturist.

${ }^{4}$ Associate professor.

${ }^{5}$ Horticultural extension agent. based primarily on fruit size and cultivar distribution. All three bear large $(>1.5 \mathrm{~g})$ fruit, are grown commercially in all five states, and represent differences in distribution in new acreage: 'Crowley' acreage is declining, 'Pilgrim' acreage is expanding steadily, and 'Stevens' acreage is increasing rapidly (Ocean Spray Cranberries, Inc., unpublished data).

\section{Materials and Methods}

Cranberry fruit mass development was studied during the 1992 and 1993 growing seasons. Sample collection sites for each cultivar were chosen in each major U.S. cranberry growing area: Massachusetts (MA), Wisconsin (WI), New Jersey (NJ), Oregon (OR), and Washington (WA). At each site, a weed-free, 225- $\mathrm{m}^{2}$ area of uniform canopy in the cranberry bed was flagged in the spring. On each collection date, five replicate samples consisting of all of the fruit from a randomly selected $0.09-\mathrm{m}^{2}$ area within the flagged site were harvested for each cultivar in each state. Samples were collected weekly beginning 4 weeks (1992) or 2 weeks (1993) after $30 \%$ out-of-bloom (OOB) and ending at commercial harvest. Percent OOB was calculated by randomly selecting 10 flowering uprights and dividing the number of set fruit by the total number of set fruit plus open blossoms plus unopened flower buds. 
Table 1. Significance of cultivar, state, collection date, and year effects on fresh, dry, and moisture mass accumulation of cranberry fruit.

\begin{tabular}{|c|c|c|c|c|c|c|c|}
\hline \multirow[b]{2}{*}{ Source of variation } & \multirow[b]{2}{*}{ df } & \multicolumn{2}{|c|}{ Fresh mass } & \multicolumn{2}{|c|}{ Dry mass } & \multicolumn{2}{|c|}{ Moisture mass } \\
\hline & & SS & F value & SS & F value & SS & F value \\
\hline State $(\mathrm{S})$ & 4 & 5.833 & $48.89^{* * *}$ & 0.112 & $84.13^{* *}$ & 5.989 & $59.54^{* * *}$ \\
\hline Cultivar (C) & 2 & 0.894 & $14.98^{* * *}$ & 0.007 & $10.10^{* * *}$ & 0.515 & $10.24^{* *}$ \\
\hline Julian date (D) & 1 & 128.2 & $4296^{* *}$ & 1.675 & $5044^{* *}$ & 75.26 & $2293^{* *}$ \\
\hline $\mathrm{D} \times \mathrm{S}$ & 4 & 8.287 & $69.46^{* *}$ & 0.142 & $106.8^{* *}$ & 8.714 & $86.63^{* * *}$ \\
\hline $\mathrm{D} \times \mathrm{C}$ & 2 & 1.606 & $26.92^{* *}$ & 0.012 & $17.54^{* *}$ & 0.848 & $16.86^{* *}$ \\
\hline $\mathrm{S} \times \mathrm{C}$ & 8 & 0.551 & $2.31^{*}$ & 0.009 & $3.36^{* *}$ & 0.373 & $1.86^{\mathrm{NS}}$ \\
\hline $\mathrm{D} \times \mathrm{S} \times \mathrm{C}$ & 8 & 0.729 & $3.05^{* *}$ & 0.011 & $4.22^{* *}$ & 0.507 & $2.52^{*}$ \\
\hline Year $(\mathrm{Y})$ & 1 & 3.288 & $110.3^{* *}$ & 0.006 & $18.46^{* *}$ & 3.814 & $151.7^{* *}$ \\
\hline $\mathrm{C} \times \mathrm{Y}$ & 2 & 0.065 & $1.10^{\mathrm{NS}}$ & 0.001 & $2.07^{\mathrm{Ns}}$ & 0.088 & $1.75^{\mathrm{NS}}$ \\
\hline $\mathrm{S} \times \mathrm{Y}$ & 4 & 1.897 & $15.90^{* *}$ & 0.006 & $5.83^{* *}$ & 0.348 & $4.61^{* *}$ \\
\hline $\mathrm{D} \times \mathrm{Y}$ & 1 & 3.095 & $103.8^{* *}$ & 0.005 & $15.60^{* *}$ & 4.195 & $166.8^{* * *}$ \\
\hline $\mathrm{D} \times \mathrm{C} \times \mathrm{Y}$ & 2 & 0.037 & $0.62^{\mathrm{NS}}$ & 0.002 & $2.55^{\mathrm{NS}}$ & 0.108 & $2.15^{\mathrm{NS}}$ \\
\hline $\mathrm{D} \times \mathrm{S} \times \mathrm{Y}$ & 4 & 2.462 & $20.64^{* *}$ & 0.001 & $1.46^{\mathrm{NS}}$ & 0.519 & $6.89^{* *}$ \\
\hline $\mathrm{S} \times \mathrm{C} \times \mathrm{Y}$ & 8 & 0.338 & $1.42^{\mathrm{NS}}$ & 0.004 & $2.24^{*}$ & 0.199 & $1.32^{\mathrm{NS}}$ \\
\hline $\mathrm{D} \times \mathrm{S} \times \mathrm{C} \times \mathrm{Y}$ & 8 & 0.534 & $2.24^{*}$ & 0.005 & $2.76^{*}$ & 0.210 & $1.39^{\mathrm{NS}}$ \\
\hline Error & 1652 & 49.271 & & 0.497 & & 37.618 & \\
\hline
\end{tabular}

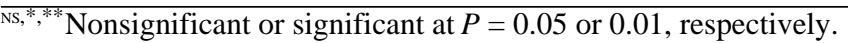

Beginning and ending collection dates for 1992 were MA, 3 Aug. and 28 Sept.; WI, 10 Aug. and 4 Oct.; NJ, 28 July and 29 Sept.; OR, 16 June and 8 Sept.; WA, 30 June and 6 Oct. The beginning and ending collection dates for 1993 were MA, 7 July and 7 Oct.; WI, 26 July and 27 Sept.; NJ, 1 July and 30 Sept.; OR, 6 July and 29 Sept.; WA, 16 June and 13 Oct.

From each sample of collected fruit, 50 berries were randomly selected to determine fresh mass. Each fruit was punctured with a dissecting needle and dried at $60^{\circ} \mathrm{C}$ for 3 to $4 \mathrm{~d}$ to constant weight. Moisture mass was calculated by subtraction of dry mass from fresh mass. Growth rates were determined from the fresh mass data using methods described in Hunt (1982).

Weather data were collected at or near the sampling sites in each state. Temperature variables recorded or calculated included: ambient maximum and minimum daily temperatures; average daily air temperature $\left[\left(\mathrm{T}_{\max }+\mathrm{T}_{\min }\right) / 2\right]$; and growing degree days (GDD) calculated by the standard method (Perry et al., 1986, method 1) using ambient temperature and a $7^{\circ} \mathrm{C}$ base temperature (DeMoranville, 1992). Pilcher (1985) reported that the geographic range for cranberry growth is limited to areas with an average daily maximum temperature less than $86^{\circ} \mathrm{F}\left(30^{\circ} \mathrm{C}\right)$ in July. Based on his assessment of the negative impact of extreme temperature, we determined the number of days exceeding extreme highs and lows in July and August from the weather data, using a daily maximum of $30^{\circ} \mathrm{C}$ as the high extreme and a daily minimum of $16^{\circ} \mathrm{C}\left(60^{\circ} \mathrm{F}\right)$ as the low extreme. To further study the 16 to $30^{\circ} \mathrm{C}$ temperature range, we calculated heat units for WI and WA (two growth rate extremes) using a method in which the differences between the daily maximum temperature up to a ceiling temperature (here 30 ${ }^{\circ} \mathrm{C}$ ) and a moderate base temperature (here $16{ }^{\circ} \mathrm{C}$ ) were summed (Perry et al., 1986, method 3). Daily and seasonal average relative humidity and seasonal total rainfall were also recorded. Solar intensity data were recorded in incompatible units from state to state (WA, WI, NJ $=\mathrm{W} \cdot \mathrm{m}^{-2}$ : average daily solar intensity, OR, MA $=\mathrm{MJ} \cdot \mathrm{m}^{-2}$ : total daily solar intensity). Data were not available for 1992 in MA and for 1993 in NJ. For comparisons among states, average daily solar intensity $\left(\mathrm{W} \cdot \mathrm{m}^{-2}\right)$ was converted to daily total solar intensity $\left(\mathrm{MJ} \cdot \mathrm{m}^{-2}\right)$ and the data for each state were separated into four intensity levels: low $=\left\langle 10 \mathrm{MJ} \cdot \mathrm{m}^{-2} ;\right.$ medium $=10-17$ $\mathrm{MJ} \cdot \mathrm{m}^{-2} ;$ high $=18-25 \mathrm{MJ} \cdot \mathrm{m}^{-2}$; very high $>25 \mathrm{MJ} \cdot \mathrm{m}^{-2}$.
Statistical analyses were performed using SAS for the personal computer (SAS Institute, Cary, N.C.). Fresh mass, dry mass, and moisture mass data were subjected to analysis of covariance (SAS GLM procedure) using a $5 \times 3 \times 2$ factorial design with state, cultivar, and year as the discrete variables and Julian date (date of data collections) as a regression covariate variable (Table 1). Based on that analysis, there were significant interactions between the covariate and the discrete variables (slopes differences). Data were then separated into groups for each state-year combination and analysis of covariance was repeated to compare differences in growth rate (slope) among cultivars. When these analyses showed significant differences among slopes (significant $\mathrm{F}$ test for the interaction of the covariate, Julian date, with cultivar in PROC GLM), the analysis of covariance was repeated for each possible cultivar pair within that state-year to separate slope differences

Table 2. Mean rate of fresh mass increase $\left(\mathrm{g} \cdot \mathrm{d}^{-1}\right)$, slopes from linear regression. Analysis of covariance comparison of cultivars within states.

\begin{tabular}{lccc}
\hline \hline State & Cultivar & 1992 & 1993 \\
\hline Wisconsin & Crowley & $0.013 \mathrm{~b}^{\mathrm{z}}$ & $0.016 \mathrm{~b}$ \\
& Pilgrim & $0.017 \mathrm{a}$ & $0.024 \mathrm{a}$ \\
Massachusetts & Stevens & $0.013 \mathrm{~b}$ & $0.022 \mathrm{a}$ \\
& Crowley & $0.013 \mathrm{a}$ & $0.018 \mathrm{a}$ \\
& Pilgrim & $0.011 \mathrm{a}$ & $0.021 \mathrm{a}$ \\
New Jersey & Stevens & $0.011 \mathrm{a}$ & $0.020 \mathrm{a}$ \\
& Crowley & $0.009 \mathrm{~b}$ & $0.013 \mathrm{~b}$ \\
Washington & Pilgrim & $0.014 \mathrm{a}$ & $0.016 \mathrm{a}$ \\
& Stevens & $0.014 \mathrm{a}$ & $0.017 \mathrm{a}$ \\
& Crowley & $0.005 \mathrm{~b}$ & $0.011 \mathrm{~b}$ \\
Oregon & Pilgrim & $0.011 \mathrm{a}$ & $0.015 \mathrm{a}$ \\
& Stevens & $0.007 \mathrm{~b}$ & $0.013 \mathrm{a}$ \\
& Crowley & $0.006 \mathrm{~b}$ & $0.006 \mathrm{a}$ \\
& Pilgrim & $0.010 \mathrm{a}$ & $0.007 \mathrm{a}$ \\
& Stevens & $0.012 \mathrm{a}$ & $0.008 \mathrm{a}$
\end{tabular}

${ }^{\mathrm{z}}$ Separate analysis for each state, each year. Slopes within state and year followed by the same letter are not significantly different at $P<0.05$ based on analysis of covariance for each possible slope pair within state and year. 
Table 3. Mean rate of fresh mass increase $\left(\mathrm{g} \cdot \mathrm{d}^{-1}\right)$, slopes from linear regression. Analysis of covariance comparison of states within cultivar.

\begin{tabular}{lccc}
\hline \hline Cultivar & State & 1992 & 1993 \\
\hline Crowley & Wisconsin & $0.013 \mathrm{a}^{\mathrm{z}}$ & $0.016 \mathrm{a}$ \\
& Massachusetts & $0.013 \mathrm{a}$ & $0.018 \mathrm{a}$ \\
& New Jersey & $0.009 \mathrm{~b}$ & $0.013 \mathrm{~b}$ \\
& Washington & $0.005 \mathrm{c}$ & $0.011 \mathrm{~b}$ \\
Pilgrim & Oregon & $0.006 \mathrm{bc}$ & $0.006 \mathrm{c}$ \\
& Wisconsin & $0.017 \mathrm{a}$ & $0.024 \mathrm{a}$ \\
& Massachusetts & $0.011 \mathrm{bc}$ & $0.021 \mathrm{a}$ \\
& New Jersey & $0.014 \mathrm{ab}$ & $0.016 \mathrm{~b}$ \\
& Washington & $0.011 \mathrm{c}$ & $0.015 \mathrm{~b}$ \\
Stevens & Oregon & $0.010 \mathrm{c}$ & $0.007 \mathrm{c}$ \\
& Wisconsin & $0.013 \mathrm{a}$ & $0.022 \mathrm{a}$ \\
& Massachusetts & $0.011 \mathrm{a}$ & $0.020 \mathrm{a}$ \\
& New Jersey & $0.014 \mathrm{a}$ & $0.017 \mathrm{~b}$ \\
& Washington & $0.007 \mathrm{~b}$ & $0.013 \mathrm{c}$ \\
& Oregon & $0.012 \mathrm{a}$ & $0.008 \mathrm{~d}$ \\
& & &
\end{tabular}

${ }^{\mathrm{z}}$ Separate analysis for each cultivar, each year. Means within a group followed by the same letter are not significantly different at $P<0.05$ based on analysis of covariance for each possible slope pair within cultivar and year.

(Table 2). Data were also separated into groups for each cultivaryear combination and subjected to analysis of covariance to compare differences in growth rate among states. When the interaction between covariate and state was significant, the analysis was repeated for each state pair to separate slope differences (Table 3).

Stepwise regression models were calculated using PROC REG with the stepwise option. This analysis uses a modified forward stepwise regression technique in which variables that meet the 0.15 significance level are included in the model sequentially. As each new variable is added, all previously included variables are reevaluated. Variables are added only if they meet the entry criterion and increase the overall significance level of the model. Variables are retained in the final model only if they are significant at the 0.1 level. The models selected with the stepwise option were checked using the maxr option of PROC REG.

Fig. 1. Fresh mass accumulation by cranberry fruit. (top) Fresh mass accumulation in three cultivars by season (datafrom states combined), observed means (Pilgrim', $\boldsymbol{\Delta}$ 'Stevens', (Crowley') and calculated regression lines (__ 'Pilgrim',_-_ 'Stevens', ........ 'Crowley'). Regression relationships: 1992, 'Pilgrim' $-\mathrm{y}=-1.73+$ $0.0126 \mathrm{x}, R^{2}=0.86$; 'Stevens'-y = - $1.40+0.0112 \mathrm{x}, R^{2}$ $=0.79$; 'Crowley' $-\mathrm{y}=-1.20+0.0092 \mathrm{x}, R^{2}=0.93 ; 1993$, 'Pilgrim'- $\mathrm{y}=-2.77+0.0166 \mathrm{x}, R^{2}=0.52$; 'Stevens'$\mathrm{y}=-2.55+0.0159 \mathrm{x}, R^{2}=0.78$; 'Crowley' $-\mathrm{y}=-2.00$ $+0.0127 \mathrm{x}, R^{2}=0.57$. (bottom) Fresh mass accumulation in five states by season (data from cultivars combined), observed means [ $\mathbf{W}$ Wisconsin (WI), * Massachusetts (MA), New Jersey (NJ), Washington (WA), $\boldsymbol{\Delta}$ Oregon (OR)] and calculated regression lines (- - WI, -- MA, --- NJ, ........ WA, — OR). Regression relationships: 1992 , WI $-\mathrm{y}=-2.20+0.0142 \mathrm{x}, R^{2}=0.93$; $\mathrm{MA}-\mathrm{y}=-1.63+0.0116 \mathrm{x}, R^{2}=0.63 ; \mathrm{NJ}-\mathrm{y}=-1.68+$ $0.0123 \mathrm{x}, R^{2}=0.90 ; \mathrm{OR}-\mathrm{y}=-1.10+0.0094 \mathrm{x}, R^{2}=0.86$; $\mathrm{WA}-\mathrm{y}=-0.61+0.0075 \mathrm{x}, R^{2}=0.89 ; 1993, \mathrm{WI}-\mathrm{y}=-$ $3.64+0.0205 \mathrm{x}, R^{2}=0.92 ; \mathrm{MA}-\mathrm{y}=-3.07+0.0195 \mathrm{x}, R^{2}$ $=0.86 ; \mathrm{NJ}-\mathrm{y}=-2.38+0.0152 \mathrm{x}, R^{2}=0.93 ; \mathrm{OR}-\mathrm{y}=-$ $0.91+0.0073 \mathrm{x}, R^{2}=0.92 ; \mathrm{WA}-\mathrm{y}=-2.20+0.0128 \mathrm{x}, R^{2}$ $=0.97$.
For a given number of variables, this option selects the model with the greatest $R^{2}$ value. In all cases, the models presented in this paper were selected by both options of PROC REG.

Temperature variables included in the model analyses were average daily temperature, average maximum temperature, average minimum temperature, days with maximum temperature above $30{ }^{\circ} \mathrm{C}$, and days with minimum temperature below $16^{\circ} \mathrm{C}$ for July, August, and the two months combined. Solar radiation variables used in the analyses were daily solar intensity-average for July and August and days with total solar intensity below $10 \mathrm{MJ} \cdot \mathrm{m}^{-2}$, between 18 and $25 \mathrm{MJ} \cdot \mathrm{m}^{-2}$, or above $25 \mathrm{MJ} \cdot \mathrm{m}^{-2}$ for July and August. Correlation coefficients among regressors and dependent variables were calculated using PROC CORR.

\section{Results and Discussion}

Fruit mass development depends on two components, accumulation of dry mass and movement of water into the developing tissue. Together these components make up the fresh mass of the fruit. In this study we examined the accumulation of fresh mass and dry mass in developing cranberry fruit. We found that the accumulation of fresh mass followed the same pattern as accumulation of dry mass for each cultivar in each state. The dry mass to fresh mass ratio remained very stable over time with a value of 0.1 . The exception to this stable ratio occurred at very early stages of fruit development, when dry mass accumulation rate was usually greater than the rate of moisture accumulation and varied from state to state. On the initial collection date dry mass to fresh mass ratios ranged from 0.1 to 0.7 . Due to data collection protocols calling for fruit collection to start well after fruit set (2 or 4 weeks after $30 \%$ OOB) and because cranberries bloom and set fruit over an extended period (up to 1 month in the Pacific Northwest), it is impossible to draw conclusions regarding the initial stages of fruit development in cranberry based on this research. To document these differences would require measuring individual fruit over time, not done in this project. Also, the combination of delayed sampling and prolonged fruit set obscured minor changes in fruit mass. This effect may have contributed to our finding that the

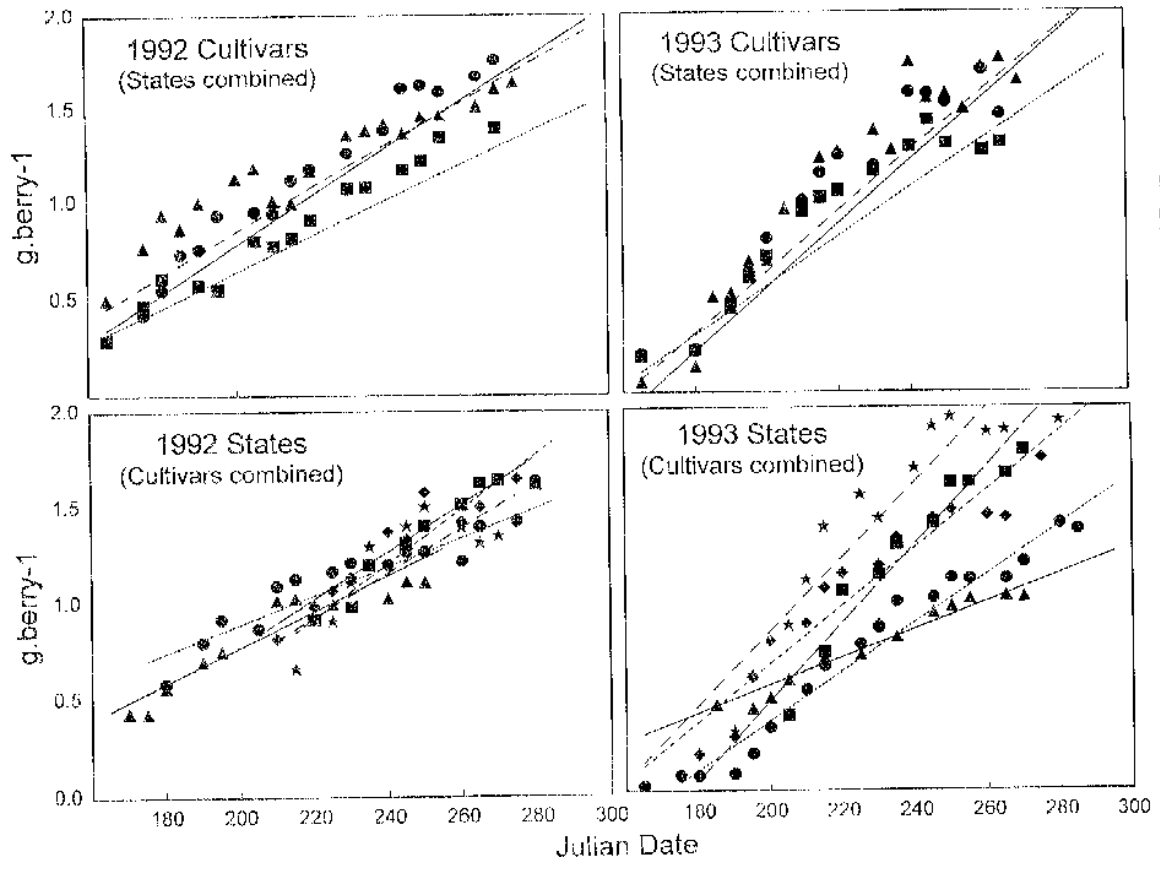


Table 4. Mass accumulation by cranberry fruit (cultivars combined).

\begin{tabular}{|c|c|c|c|c|c|c|c|c|c|c|}
\hline \multirow[b]{3}{*}{ State } & \multicolumn{4}{|c|}{$30 \%$ OOB + 4 weeks ${ }^{z}$} & \multirow{2}{*}{\multicolumn{2}{|c|}{$\begin{array}{c}\text { Time to accumulate } \\
\text { additional } \\
0.5 \mathrm{~g} \text { fresh mass }\end{array}$}} & \multirow{3}{*}{$\begin{array}{c}\text { Last } \\
\text { collection } \\
\text { Julian date }\end{array}$} & \multirow{2}{*}{\multicolumn{3}{|c|}{$\begin{array}{l}\text { Fresh mass } \\
\quad \text { linear } \\
\text { regression }\end{array}$}} \\
\hline & \multirow[b]{2}{*}{ Julian date } & \multirow{2}{*}{$\begin{array}{l}\text { Fresh } \\
\text { mass } \\
(\mathrm{g})\end{array}$} & \multirow{2}{*}{$\begin{array}{l}\text { Dry } \\
\text { mass } \\
(\mathrm{g})\end{array}$} & \multirow{2}{*}{$\begin{array}{l}\text { Moisture } \\
\text { mass } \\
\text { (g) }\end{array}$} & & & & & & \\
\hline & & & & & GDD $^{x}$ & Days & & Y intercept & Slope & $r^{2}$ \\
\hline \multicolumn{11}{|c|}{1992} \\
\hline Wisconsin & 223 & 0.92 & 0.09 & 0.83 & 338 & 35 & 278 & -2.20 & 0.014 & 0.93 \\
\hline Massachusetts & 216 & 0.66 & 0.07 & 0.59 & 269 & 21 & 272 & -1.63 & 0.012 & 0.65 \\
\hline New Jersey & 210 & 0.82 & 0.08 & 0.75 & 386 & 28 & 273 & -1.68 & 0.012 & 0.90 \\
\hline Washington & 182 & 0.58 & 0.06 & 0.52 & 245 & 28 & 280 & -0.72 & 0.008 & 0.89 \\
\hline Oregon & 175 & 0.43 & 0.05 & 0.38 & 294 & 35 & 252 & -1.02 & 0.009 & 0.89 \\
\hline \multicolumn{11}{|c|}{1993} \\
\hline Wisconsin & 221 & 1.04 & 0.10 & 0.93 & 311 & 24 & 270 & -3.64 & 0.021 & 0.93 \\
\hline Massachusetts & 203 & 0.86 & 0.07 & 0.79 & 212 & 14 & 280 & -2.62 & 0.017 & 0.86 \\
\hline New Jersey & 196 & 0.58 & 0.06 & 0.53 & 361 & 23 & 273 & -2.38 & 0.015 & 0.92 \\
\hline Washington & 202 & 0.32 & 0.03 & 0.29 & 278 & 28 & 286 & -2.15 & 0.013 & 0.97 \\
\hline Oregon & 194 & 0.42 & 0.05 & 0.37 & 508 & 49 & 272 & -1.04 & 0.008 & 0.94 \\
\hline
\end{tabular}

${ }^{\mathrm{z}} \mathrm{OOB}=$ out of bloom. Data collection began 2 weeks earlier in 1993. For ease of comparison, first 2 weeks of 1993 data omitted here.

yFrom model: fresh mass = intercept + slope (Julian date). Depending on state and year, $\mathrm{n}$ ranged from 135 to 225.

${ }^{\mathrm{x}} \mathrm{GDD}=$ growing degree days.

pattern of fresh mass accumulation was best described by a linear function (Fig. 1) rather than a sigmoidal or exponential function as reported for other fruits (Bollard, 1970). Hawker and Stang (1985) also showed a linear relationship between fresh or dry mass accumulation of 'Searles' and 'Ben Lear' cranberries and GDD (9 to $32{ }^{\circ} \mathrm{C}$ range).

Because the ratio of dry mass to fresh mass was stable during the data collection period, we concentrated our data evaluation on the accumulation of fresh mass in cranberry fruit. We looked for developmental differences based on cultivar, growing region, or their interaction. Analysis of covariance models indicated that the level of significance for the variables year, cultivar, state, and Julian date were similar for fresh, dry, or water mass accumulation with some exceptions (Table 1). Differences in significance between fresh and dry mass were only found for some interactions involving state. Although all sampling began at the same stage, based on \%OOB, variation existed due to differences in the initial, rate of mass accumulation, e.g., slower in the Pacific Northwest than in the Eastern States. This led to lower starting masses for OR, and WA (Table 4). When fruit mass was low, dry to fresh mass; ratios were more variable.

Fresh mass accumulation differed among cultivars within states (Table 3) and across states (Fig. 1, top half). Fresh mass accumu-" lation relationships among the three cultivars (states combined) did not vary in the two years studied (Table 1 , day $\times$ cultivar $\times$. year). Analysis of covariance of the across-state data showed that; the larger fruited cultivars, Stevens and Pilgrim, had similar. growth curves with steeper slopes than that of 'Crowley' in both, years (Fig. 1). When the cultivar data were evaluated within states,' the slower growth rate for 'Crowley' compared to that of 'Stevens' ' and 'Pilgrim' was found for two states in 1992 and three states in 1993 (Table 2). In the other state-year combinations, all three cultivars had similar growth rates or the growth rates of 'Crowley' and 'Stevens' were similar and lower than that of 'Pilgrim'.

Several trends in the data for cranberry fruit development by state (cultivars combined) were of interest (Fig. 1, bottom and Table 4). The data formed two groups by state: the Pacific Northwest (WA and OR) and the Eastern States (MA, NJ, and WI). Analysis of covariance of the state data across cultivar (slopes from
Fig. 1, bottom) showed that in 1992 cranberries in WI and NJ had higher growth rates than those in WA and OR with MA falling between. In 1993, WI and MA fruit showed the highest growth rates followed by $\mathrm{NJ}$, WA, and OR (all different from each other and from WI and MA). The shorter growing seasons in the Eastern States, especially WI, seem to be compensated for by more rapid growth rates (Fig. 2, WI). Conversely, low initial mass and a slower growth rate (Fig. 2, WA) can be overcome by a longer growing season. Mean growth rates in 1992 and 1993 (Table 3) tended to be inversely related to length of growing season (Table 4) for all three cultivars, with the lowest growth rates often occurring in WA and OR where the growing season $(30 \%$ OOB + 4 weeks to harvest) was the longest.

The number of days for the fruit to develop an additional $0.5 \mathrm{~g}$ of fresh mass from the $30 \% \mathrm{OOB}+4$ week starting point varied

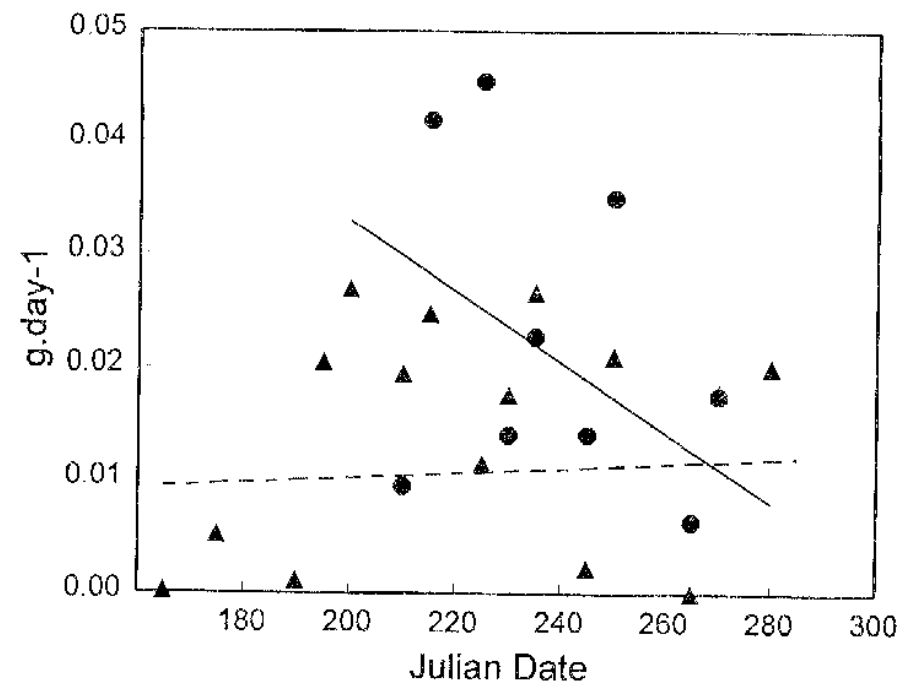

Fig. 2. Cranberry fresh mass growth rate extremes as illustrated by three cultivars in Wisconsin (WI) and Washington (WA) (1993 data, cultivars combined). Observed means ( WI, $\boldsymbol{\Delta}$ WA) and calculated regression ( - WI, - - - WA). $R^{2}$ values: $\mathrm{WI}=0.44, \mathrm{WA}=0.01$ (not significant). 
Table 5. Daily total solar intensity: monthly averages for July and August 1992 and 1993.

\begin{tabular}{lccccc}
\hline \hline & \multicolumn{4}{c}{$\begin{array}{c}\text { Daily total solar intensity } \\
\left(\mathrm{MJ} \cdot \mathrm{m}^{-2}\right)\end{array}$} \\
\cline { 2 - 4 } \cline { 5 - 6 } & \multicolumn{3}{c}{ July } & & August \\
\cline { 2 - 3 } State & 1992 & 1993 & & 1992 & 1993 \\
\hline Wisconsin & 19.5 & 17.8 & & 19.8 & 15.8 \\
Massachusetts & --- & 29.5 & --- & 26.7 \\
New Jersey & 23.4 & --- & 18.3 & --- \\
Washington & 21.4 & 17.4 & 20.9 & 17.4 \\
Oregon & 22.2 & 21.6 & 20.8 & 24.0 \\
\hline
\end{tabular}

with year and state (Table 4). Growing degree days were calculated in an attempt to explain the year to year differences within a state and among the states in number of days needed to accumulate 0.5 $\mathrm{g}$ fresh mass. The GDD data were no more uniform than the data for number of days comparing MA to other states and for two seasons (Table 4).

Solar intensity was recorded in $\mathrm{W} \cdot \mathrm{m}^{-2}$ (WI, WA, NJ) or MJ $\cdot \mathrm{m}^{-2}$ (OR, MA). Data were converted to daily total solar intensity $\left(\mathrm{MJ} \cdot \mathrm{m}^{-2}\right)$ as necessary. The monthly means for July and August are shown in Table 5 . When solar intensity data were divided into four ranges (low to very high), states could be compared. OR, MA, NJ, and WI (1992 only) had solar intensity in high or very high ranges on $>20 \mathrm{~d}$ in July and August. WI and WA had the lowest average total daily solar intensities, especially in 1993 (Table 5). Solar intensity groupings did not correspond to the east-west grouping of the growth data. Further examination of the data (Tables 4 and 5) showed that high average total daily solar intensity occurred at locations with rapid fruit mass accumulations (MA, NJ) and at locations with slow mass accumulation (OR, WA in 1992). WI had slow growth and high solar intensity in 1992, more rapid growth and lower solar intensity in 1993.

Neither GDD nor number of days elapsed seemed to be good predictors for fresh mass accumulation in cranberry fruit. Based on a WA survey (Pilcher, 1985), we next considered looking at the weather data in a different way, concentrating on temperature extremes. Pilcher (1985) found that the ideal commercial cranberry growing regions based on current production areas were bounded by the $29^{\circ} \mathrm{C}$ July average daily maximum temperature isotherm. Based on this information, we tabulated average and average maximum temperatures for July and August (Table 6) as well as the number of days with maxima above $30^{\circ} \mathrm{C}$ (or minima below $16^{\circ} \mathrm{C}$ ) for each state and each year (Table 7). These data were used as the regressors in modified forward stepwise regression models for fresh mass development (dependent variables from Table 4). Significant models were found for days to accumulate additional $0.5 \mathrm{~g}$ fresh mass (D, Eq. [1]) and rate of fresh mass accumulation (R, Eq. [2]), with $R^{2}$ of 0.86 and 0.81 , respectively.
$R^{2}$ may be inflated due to correlation among the temperature variables.

$$
\begin{aligned}
& \mathrm{D}=-86.6+2.1 \mathrm{~A}_{16} \mathrm{D}+6.2 \mathrm{JAT}-2.1 \mathrm{AMT} \\
& \mathrm{R}=-0.0156+0.0013 \text { AMT }-0.0005 \mathrm{~J}_{30} \mathrm{D}
\end{aligned}
$$

where JAT is July average temperature, AMT is August average maximum temperature, $\mathrm{A}_{16} \mathrm{D}$ is the number of days in August with minimum temperature less than $16^{\circ} \mathrm{C}$, and $\mathrm{J}_{30} \mathrm{D}$ is the number of days in July with maximum temperature greater than $30^{\circ} \mathrm{C}$.

Stepwise regression was repeated to include solar intensity variables as regressors in addition to temperature variables. The solar radiation variables used were mean daily total solar intensity for July and August (Table 5), numbers of days in July and August below $10 \mathrm{MJ} \cdot \mathrm{m}^{-2}$, above $18 \mathrm{MJ} \cdot \mathrm{m}^{-2}$, and above $25 \mathrm{MJ} \cdot \mathrm{m}^{-2}$. Missing data (MA 1992, NJ 1993) led to only eight observations for these models. The selected variables for the fresh mass accumulation rate model (R, Eq. [2]) were unchanged when solar data were included. However, the new model for days to accumulate additional $0.5 \mathrm{~g}$ fresh mass (D, Eq. [3]) included days in July with solar intensity $<10 \mathrm{MJ} \cdot \mathrm{m}^{-2}\left(\mathrm{~J}_{10} \mathrm{~S}\right)$ and had an $R^{2}$ of 0.98 .

$\mathrm{D}=-95.1+2.3 \mathrm{~A}_{16} \mathrm{D}+7.2 \mathrm{JAT}-3.0 \mathrm{AMT}+1.7 \mathrm{~J}_{10} \mathrm{~S}$

This model (Eq. [3]) indicated that lack of sunshine in July was associated with slower fresh mass accumulation and could account for some variability not associated with temperature $\left(R^{2}\right.$ increased to 0.98 from 0.86 ) but temperature continued to account for most of the variability in the fresh mass accumulation data. Temperature and solar intensity variables were not significantly correlated.

Cultivar data for each state were combined before performing the stepwise regression analyses under the assumption that weather factors should effect all cultivars similarly. This assumption was tested by repeating the analyses using the individual cultivar data. For all three cultivars, the same variables shown in Eq. [2] were selected as predictors for growth rate. However, while the $R^{2}$ for the 'Crowley' model remained high (0.85), $R^{2}$ for the 'Pilgrim' and 'Stevens' models was 0.65 . There was more variability in cultivar models for days to accumulate $0.5 \mathrm{~g}$ fresh mass. Analysis of the 'Crowley' data gave models similar to those in Eqs. [1] and [3] with two out of three or three out of four of the same variables selected, respectively. Based on the 0.1 significance level demanded by the modeling technique, no day models were selected for 'Pilgrim' or 'Stevens'.

In some fruit crops, fruit size is effected by fruit load, e.g., the number of apples per tree affects the weight per apple (Elfving and Cline, 1993). Yield data $\left(\mathrm{kg} \cdot \mathrm{m}^{-2}\right)$ for each cultivar in each state were compiled on the final collection date. When yield was included as a variable in the stepwise regression procedure, it was not selected and the models (Eqs. [1] to [3]) remained unchanged.

\begin{tabular}{|c|c|c|c|c|c|c|c|c|}
\hline \multirow[b]{3}{*}{ State } & \multicolumn{4}{|c|}{$\operatorname{Avg~T}\left({ }^{\circ} \mathrm{C}\right)$} & \multicolumn{4}{|c|}{$\operatorname{Avg~} \mathrm{T}_{\max }\left({ }^{\circ} \mathrm{C}\right)$} \\
\hline & \multicolumn{2}{|c|}{ July } & \multicolumn{2}{|c|}{ August } & \multicolumn{2}{|c|}{ July } & \multicolumn{2}{|c|}{ August } \\
\hline & 1992 & 1993 & 1992 & 1993 & 1992 & 1993 & 1992 & 1993 \\
\hline Wisconsin & 18.2 & 20.3 & 17.9 & 19.9 & 23.1 & 25.1 & 23.6 & 25.0 \\
\hline Massachusetts & 20.3 & 22.6 & 20.4 & 22.0 & 24.9 & 27.6 & 24.3 & 27.1 \\
\hline New Jersey & 22.7 & 24.1 & 20.9 & 23.5 & 28.4 & 32.6 & 27.2 & 32.0 \\
\hline Washington & 15.2 & 15.5 & 14.1 & 16.6 & 18.3 & 18.3 & 17.9 & 20.6 \\
\hline Oregon & 15.3 & 16.9 & 14.8 & 17.7 & 18.0 & 17.6 & 18.5 & 18.4 \\
\hline
\end{tabular}

Table 6. Average temperature $(\mathrm{T})$ and maximum $\left(\mathrm{T}_{\max }\right)$ daily ambient air temperature; monthly averages for July and August 1992 and 1993. 
Table 7. Number of days with temperature extremes, based on daily maximum or minimum temperature (T).

\begin{tabular}{|c|c|c|c|c|c|c|c|c|}
\hline \multirow[b]{3}{*}{ State } & \multicolumn{4}{|c|}{ Number of days with $\mathrm{T}>30^{\circ} \mathrm{C}$} & \multicolumn{4}{|c|}{ Number of days with $\mathrm{T}<16^{\circ} \mathrm{C}$} \\
\hline & \multicolumn{2}{|c|}{ July } & \multicolumn{2}{|c|}{ August } & \multicolumn{2}{|c|}{ July } & \multicolumn{2}{|c|}{ August } \\
\hline & 1992 & 1993 & 1992 & 1993 & 1992 & 1993 & 1992 & 1993 \\
\hline Wisconsin & 0 & 0 & 1 & 1 & 28 & 18 & 27 & 16 \\
\hline Massachusetts & 2 & 7 & 0 & 2 & 15 & 10 & 14 & 11 \\
\hline New Jersey & 11 & 22 & 4 & 24 & 13 & 8 & 16 & 11 \\
\hline Washington & 0 & 0 & 1 & 1 & 30 & 31 & 27 & 31 \\
\hline Oregon & 0 & 0 & 0 & 0 & 29 & 31 & 31 & 31 \\
\hline
\end{tabular}

Further, forcing yield into the models only improved $R^{2}$ by about 0.05 . This is not unexpected as these are predictive models-final outcome (in this case, yield) is not a good predictor of prior events. Finally, Pearson correlation coefficients between yield and day (D) or rate (R) were small and not significant.

MA had lower average daily temperatures than NJ in July each year (Table 6) and fruit in MA accumulated fresh mass in fewer days than that in NJ. According to Eqs. [1] and [3], high July temperatures and low August temperatures increase the number of days to accumulate $0.5 \mathrm{~g}$ fresh mass. The MA mean growth rates for each cultivar were lower in 1992 than in 1993 (Table 3). Cooler days in August (lower AMT) in MA in 1992 than in 1993 may explain the lower mean growth rate in 1992 (Eq. [2]). The 1993 mean growth rates for 'Pilgrim' and 'Stevens' in MA (Table 3) were similar to those found for those cultivars in MA in 1989, 1990, and 1991 (DeMoranville, 1992).

WA and OR had lower average daily temperatures and lower average maxima than the other states, particularly MA and NJ (Table 6). OR and WA also had a high number of days with a minimum temperature $<16{ }^{\circ} \mathrm{C}$ (Table 7) and low maximum temperatures in August. These cool days in August may limit the growth rate of cranberries in these states, also explaining the large number of days required to achieve $0.5 \mathrm{~g}$ of fresh mass (Eq. [1] and [3]). Chandler (1952) found the growth rate for 'Early Black' cranberry in MA was $0.0185 \mathrm{~g} \cdot \mathrm{d}^{-1}$ during the warm period from mid-July to mid-August, but dropped to $0.005 \mathrm{~g} \cdot \mathrm{d}^{-1}$ later in the season when temperatures were lower. This is in agreement with our model for growth rate (Eq. [2]) which showed a positive relationship between growth rate and maximum temperatures in August.

The WI data appeared to confirm the importance of the 16 to 30 ${ }^{\circ} \mathrm{C}$ range (Table 7). WI apparently had no limitations due to high temperatures in either year $\left(\mathrm{J}_{30} \mathrm{D}=0\right)$. Low temperatures varied in 1992 and 1993 with the latter having many fewer days of $<16^{\circ} \mathrm{C}$ minima in August. The higher number of cool days in 1992 was associated with an $11 \mathrm{~d}$ longer period to achieve $0.5 \mathrm{~g}$ of fresh mass.

If moderate temperatures are key for cranberry fruit development, then the failure of standard GDD calculations (base $7^{\circ} \mathrm{C}$, no upper limit) and number of days elapsed to serve as predictors for $0.5 \mathrm{~g}$ fresh mass accumulation could be explained. We also attempted to fit heat units (GDD) to the accumulation of $0.5 \mathrm{~g}$ fresh mass data for WA and WI using method 3 of Perry et al. (1986). Using the first GDD method (sum of difference between average daily temperature and $7^{\circ} \mathrm{C}$ base temperature) there were 93 and 33 (1992 and 1993, respectively) more GDD accumulated in WI than in WA during the addition of $0.5 \mathrm{~g}$ fresh mass. Using the second method (Perry et al., 1986), there were 142 and 90 more GDD accumulated in WI in 1992 and 1993, respectively. The accumulation of $0.5 \mathrm{~g}$ fresh mass was not completed within the same number of GDD from state to state or from year to year regardless of how the GDD were calculated.

The value of using maxima and minima and Eq. [1] and [2] to predict cranberry fruit development is highlighted in a comparison of the MA, NJ, and WI data for 1993 (Tables 3, 6, and 7). NJ and WI average temperatures in July varied little $\left(2{ }^{\circ} \mathrm{C}\right)$ from those in MA. However, there were many more days with maxima $>30^{\circ} \mathrm{C}$ in NJ than in MA or WI. For all three cultivars (Table 3), mean growth rate was similar in MA and WI but lower in NJ. Average temperature (Table 6) or GDD (Table 4) comparisons could not have predicted this observation.

July and August temperatures, in particular the 16 to $30{ }^{\circ} \mathrm{C}$ range, accounted for $>80 \%$ of the variability in cranberry fresh mass accumulation in this study. Solar radiation intensity appeared less important. High temperatures limited cranberry fruit growth in NJ. Low temperatures were limiting in OR and WA, and for one season in WI. MA had the fewest temperature extremes in both seasons, resulting in the shortest number of days required to accumulate $0.5 \mathrm{~g}$ fresh mass.

\section{Literature Cited}

Bollard, E.G. 1970. The physiology and nutrition of developing fruits, p. 387-425. In: A.C. Hulme (ed.). The biochemistry of fruits and their products. Academic Press, New York.

Chandler, F.B. 1952. Preliminary report on the development of cranberry fruit. Cranberries 17(4):6-7.

DeMoranville, C.J. 1992. Cranberry nutrients, phenology, and nitrogenphosphorus-potassium fertilization. PhD diss., Univ. of Massachusetts, Amherst.

Eck, P. 1990. The American cranberry. Rutgers Univ. Press, New Brunswick, N.J.

Elfving, D.C. and R.A. Cline. 1993. Cytokinin and ethephon affect crop load, shoot growth, and nutrient concentration of 'Empire' apple trees. HortScience 28:1011-1014.

Hawker, G.M. and E.J. Stang. 1985. Characterizing vegetative growth and fruit development in cranberry (Vaccinium macrocarpon Ait.) by thermal summation. Acta Hort. 165:311-324.

Hunt, R. 1982. Plant growth curves: The functional approach to plant growth analysis. Univ. Park Press, Baltimore, Md.

Perry, K.B., T.C. Wehner, and G.L. Johnson. 1986. Comparison of 14 methods to determine heat unit requirements for cucumber harvest. HortScience 21:419-423.

Pilcher, L.S. 1985. Appraising sites for cranberry culture using seasonal temperature and daylength data. MS thesis, Western Washington Univ., Bellingham. 